Bol. Acad. peru. leng. 66. 2019 (231-254)

\title{
LAS ACADEMIAS DE PERÚ Y CHILE PATROCINARON EL XIV CONGRESO INTERNACIONAL DE LEXICOLOGÍA Y LEXICOGRAFÍA EN LIMA
}

\author{
Jorge Ignacio Covarrubias
}

Academia Norteamericana de la Lengua

Fecha de recepción:

$19 / 10 / 2019$

Fecha de aceptación:

$30 / 11 / 2019$

Las Academias de la Lengua de Perú y de Chile organizaron el XIV Congreso Internacional de Lexicología y Lexicografía «Humberto López Morales. La aventura del español en América», que sesionó a sala llena del 9 al 11 de octubre de 2019, en el auditorio del Instituto Cultural Peruano Norteamericano en Lima.

El presidente de la Academia Peruana de la Lengua, Marco Martos Carrera, aprovechó la presencia de sus colegas invitados: Adriana Valdés Budge, directora de la Academia Chilena, y Alfredo Matus Olivier, director honorario de la academia hermana, como también de Jorge Ignacio Covarrubias, secretario general de la Academia Norteamericana, para que lo acompañaran en la entrega de los premios del III Concurso Literario Escolar en la sede de la Academia Peruana, un acto paralelo al Congreso.

https://doi.org/10.46744/bapl.201902.009

e-ISSN: 2708-2644 
Durante los tres días de sesiones se escucharon veintiuna ponencias de alto nivel de 29 especialistas de once universidades. Once de los ponentes representaron a la Universidad Nacional Mayor de San Marcos y uno a la Universidad de Poznán, en Polonia. También, expusieron representantes de la Pontificia Universidad Católica de Perú (PUCP), la Universidad Peruana de Ciencias Aplicadas, la Universidad Ricardo Palma, la Universidad de Piura, la Universidad Nacional de Educación Enrique Guzmán y Valle, la Universidad Nacional del Altiplano, la Universidad Nacional Agraria La Molina, la Universidad del Pacífico y la Universidad Católica Santo Toribio de Mongrovejo (USAT).

Marco Martos Carrera abrió el Congreso el 9 de octubre en nombre de la Academia Peruana y Alfredo Matus Olivier pronunció la conferencia de inauguración. Adriana Valdés Budge tuvo a su cargo la conferencia de clausura y Jorge Ignacio Covarrubias presentó una semblanza ilustrada de Humberto López Morales, destacado lingüista y exsecretario general de la Asociación de Academias de la Lengua (ASALE), cuyo nombre llevó el Congreso en homenaje a su persona. Magaly Rueda, asistente de la Academia Peruana, participó activamente en la organización.

El presidente de la Academia Peruana de la Lengua dio comienzo al Congreso recordando que el escritor Ricardo Palma fundó la institución en 1867 y que quince años más tarde «llevó a la Real Academia Española varios peruanismos, ninguno de los cuales fue aceptado». Pero aclaró que después que en 1951 se instituyó la Asociación de Academias de la Lengua gracias a la gestión del entonces presidente mexicano Miguel Alemán, «la actitud de la RAE ha variado con el tiempo». En su breve presentación reveló que alentaba el sueño de un diccionario del español del Perú.

Alfredo Matus Olivier, director honorario de la Academia Chilena que dirigió durante varios años, tituló su conferencia de inauguración «Para una concepción integral de la política panhispánica». 


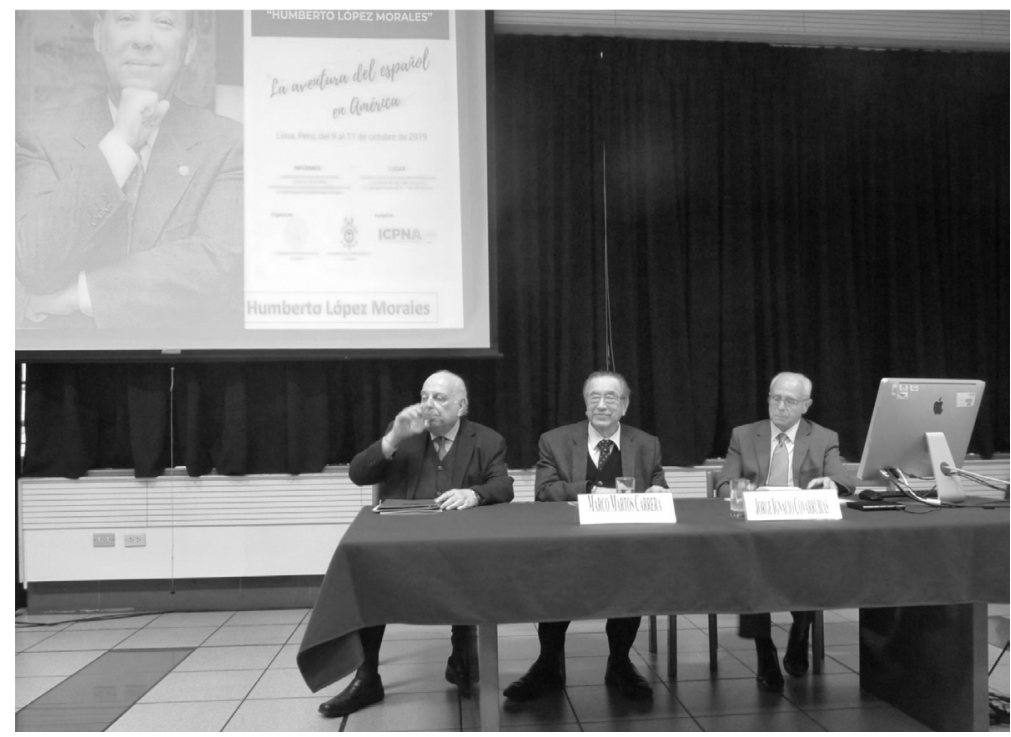

«Humberto López Morales ha sido uno de los lingüistas más comprometidos con la política panhispánica: su trabajo La aventura del español en América (1998) así lo comprueba», afirmó. "Esta verdadera teoría de la lengua española hoy, concepción fundada en las ciencias del lenguaje contemporáneas y de inspiración neobellista, fraguada en las últimas décadas, con relevantes antecedentes y pioneros de la Real Academia y de la Asociación de Academias de la Lengua Española, está en la base del actual paradigma hermenéutico del llamado español de América».

La presentación del director honorario de la Academia Chilena se propuso situar las discusiones sobre norma y uso dentro de un marco integral del fenómeno lingüístico, tratando de superar el tradicional reduccionismo de la competencia al valor de «lo correcto». Afirmó que «el gran teórico del lenguaje y destacado hispanista, Eugenio Coseriu, desarrolló un modelo sobre los criterios de valoración comunicativa, todavía 
poco difundido, en el que la competencia idiomática debe ser asumida, científica y, prácticamente, a partir de un esquema integral transversal que considera la competencia elocucional (del «hablar en general») y la competencia expresiva (del «hablar en situaciones concretas»).

Matus agregó que «hacer diccionarios es la principal tarea de las academias» y aclaró que todas las 23 academias participan en la actualización del Diccionario de la Lengua Española (DLE). Dijo que el Diccionario de americanismos, que dirigió Humberto López Morales es descriptivo y carece de propósito normativo, en contraste con el Diccionario panbispánico de dudas que es normativo, aunque precisó que «todo diccionario tiene esa dimensión normativa que da la descripción».

A continuación, Jorge Ignacio Covarrubias trazó una semblanza de Humberto López Morales con fotografías que iban desde cuando el homenajeado tenía seis años en La Habana hasta su residencia actual en Miami. En la presentación destacó que el lingüista, autor de más de 40 libros, con 17 doctorados honoris causa, y miembro de once academias de la lengua, pese a ser cubano desarrolló toda su carrera académica como numerario de la Academia Puertorriqueña. Sin embargo, presentó un testimonio del director de la Academia Cubana de la Lengua, Rogelio Rodríguez Coronel, quien afirmó que las relaciones con él fueron excelentes. El secretario general de la Academia Norteamericana de la Lengua concluyó su intervención con jocosas anécdotas de López Morales, que a su erudición unía un profundo sentido del humor.

A partir de entonces y a lo largo de tres días se escucharon las 21 ponencias del Congreso. A continuación, los resúmenes que adelantaron los ponentes antes de sus presentaciones:

«Desarrollo del léxico de ciudadanía en Lengua de Señas Peruana» Miguel Rodríguez Mondoñedo y Alexandra Arnaiz F. C. (Pontificia Universidad Católica del Perú)

Este proyecto pretende desarrollar el léxico básico de ciudadanía de la Lengua de Señas Peruana (LSP). Las personas sordas se encuentran 
https://doi.org/10.46744/bapl.201902.009

aisladas, tienen escaso o nulo acceso a información básica que los oyentes dan por sentada. Por ejemplo, desconocen aspectos básicos de los derechos ciudadanos, y muchos conceptos no tienen señas. La única manera de inducir la creación de nuevas palabras es confrontar a los usuarios con necesidades nuevas. Así, desarrollamos un método para crear un léxico de ciudadanía: convocar a usuarios sordos de LSP a un taller donde se expliquen los conceptos básicos sobre este campo semántico y se identifiquen los vacíos léxicos, para los cuales se proponen señas nuevas, las cuales son validadas primero por otros grupos focales de sordos y, luego, se publican online para consideración de toda la comunidad sorda. Esta metodología, que sigue en parte la del ASL-STEM Forum (para la lengua de señas americana), nos permitirá observar el proceso de deliberación de la comunidad acerca de la creación de nuevas señas.

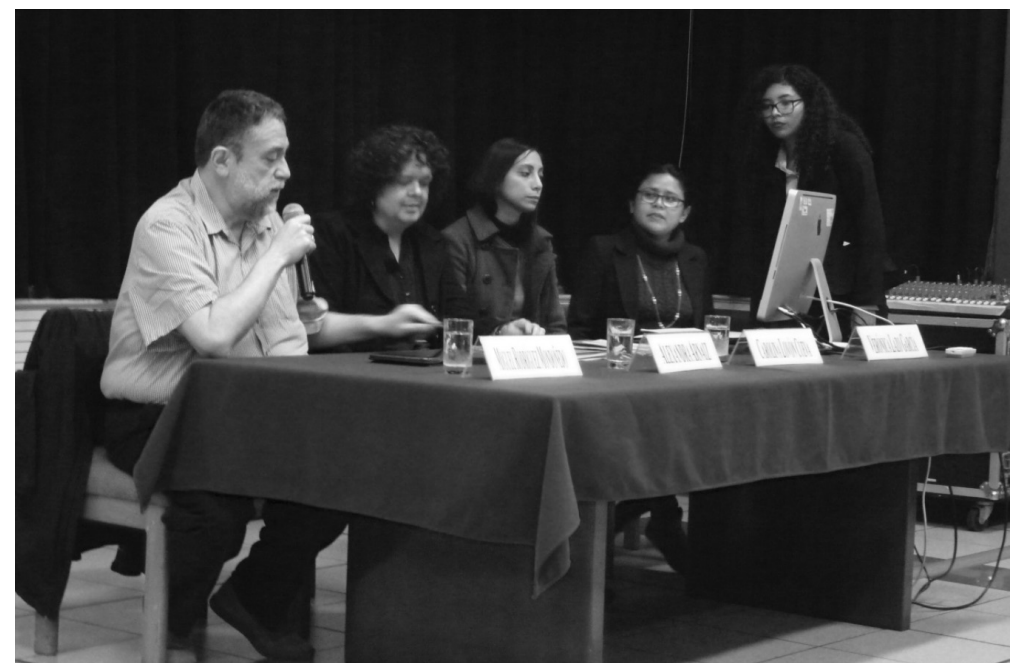

«La construcción del léxico lesbofóbico: Un estudio desde la filosofía y la lexicología»

Carolina Lovón Cueva (Universidad Peruana de Ciencias Aplicadas)

La construcción de léxico sobre la filosofía de la violencia en personas lesbianas ha surgido de las diferentes formas de descalificación y 
rechazo hacia ellas por su condición de género. Los objetivos de esta investigación son: i) identificar los constructos léxicos de la violencia contra la persona lesbiana en la sociedad actual, ii) describir la configuración léxica como problema social, y iii) analizar el impacto de difusión de los léxicos de violencia. El corpus estará compuesto por algunas evidencias de las redes sociales. Se analizarán estas configuraciones léxicas sobre la violencia ejercida en las personas lesbianas. Por último, la violencia identificada en las relaciones sociales de las personas lesbianas permite reconocer una preocupación de orden social y político.

«Aspectos cognitivos en la denominación de algunas bandas criminales peruanas»

Verónica Lazo García (Universidad Nacional Mayor de San Marcos)

Es difícil no sonreír ante los nombres de las organizaciones o bandas criminales por lo pintorescos que son: «los Babyes de Oquendo», «los Lobitos de la Corrupción», «los Malditos del Triunfo», entre otros. Estos exónimos son colocados por los policías durante su intervención. La presente ponencia tiene por objetivo aproximar los marcos conceptuales en los que se encuadran estos apodos. Se examinará la estructura, la función y los mecanismos cognitivos de los nombres de veinte bandas criminales, lo cual evidenciará que los marcos culturales se expresan en el sistema de denominación de las bandas, conteniendo una carga irónica y burlesca sobre las características socioculturales de la acción criminal.

«El uso de frases con animales en el español peruano» María Isabel Montenegro García (Universidad Ricardo Palma)

Actualmente, en la sociedad peruana, transmitir sentimientos e ideas basadas en el uso de expresiones coloquiales se ha convertido en una necesidad. En este escenario, las frases con animales tienen un propósito: responder a los intereses y necesidades comunicativas de los hablantes. En el trabajo, se presenta un corpus léxico del español peruano recogido de un determinado contexto. Ejemplo de 
https://doi.org/10.46744/bapl.201902.009

ello se tiene: «matar dos pájaros de un solo tiro», que significa hacer dos cosas a la vez; "pagar pato", asumir una responsabilidad ajena; entre otros. La investigación concluye en resaltar la importancia de su utilización como herramienta comunicacional en una esfera social determinada.

«Las valoraciones a través de voces andinas: los auquénidos en el Diccionario de la lengua española (2014)»

Xiomara Rojas (Universidad Nacional Mayor de San Marcos)

Las acepciones no solo describen una palabra, sino que, también, transmiten ideologías, valoraciones y actitudes hacia una cultura, lengua y comunidad. En el presente trabajo se analizarán las voces andinas relacionadas a los auquénidos de los Andes peruanos (vicuña, alpaca, llama, guanaco). Específicamente, se revisará el contenido de las acepciones para verificar qué valoraciones estas «esconden». Asimismo, lo encontrado se comparará con las definiciones revisadas en otros diccionarios y léxicos especializados.

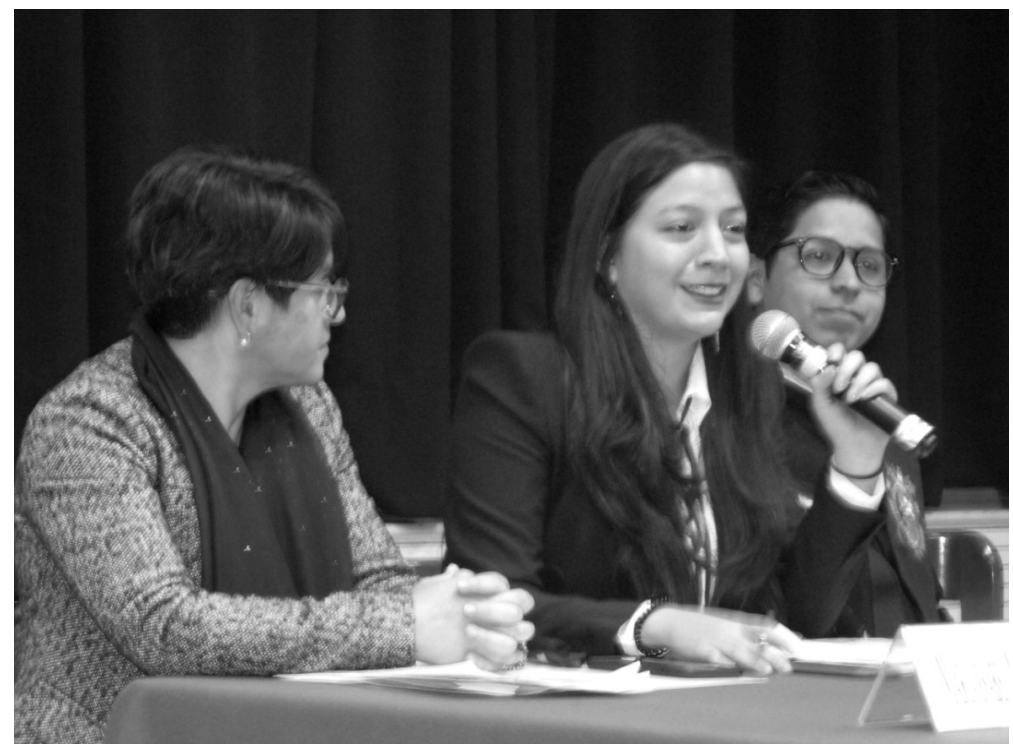


https://doi.org/10.46744/bapl.201902.009

«Los procesos semánticos del léxico de la Tuna de la Universidad Nacional Mayor de San Marcos»

Cristhian Concepción Pérez (Universidad Nacional Mayor de San Marcos)

La ponencia busca explicar el estudio del léxico de los integrantes de la Tuna de la Universidad Nacional Mayor de San Marcos (UNMSM), el cual se desempeña en el sentido de categorizar las palabras creadas por ellos mismos, considerando la data recolectada por medio de entrevistas a sus integrantes, identificando a su vez procesos semánticos en ellos que sirvan para reforzar la identidad de los estudiantes sanmarquinos y del Perú en general. Asimismo, se puede concluir que el estudio de los términos empleados por los tunos de la UNMSM hace referencia a sus actividades diarias y todo lo que involucra pertenecer a esta tradición de índole universitaria, a la vez de hallarse creatividad léxica para la producción de metáforas e hipérboles.

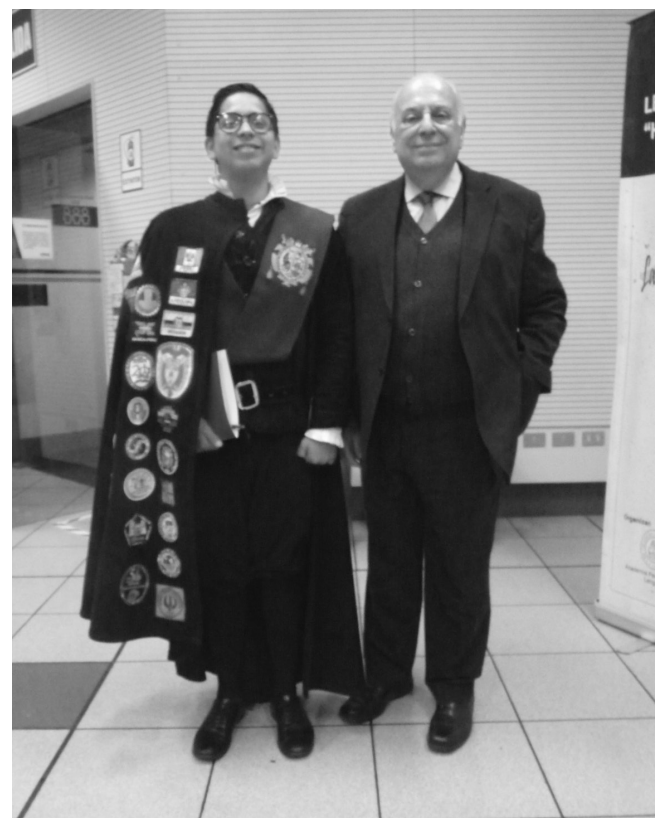


«Las perífrasis verbales más frecuentes en el castellano andino de Ayacucho» Jorge Esquivel Villafana (Universidad Nacional Mayor de San Marcos)

La perífrasis verbal es reconocida como la reunión de dos o más verbos que funcionan como el núcleo del predicado. Esta puede ser de tres clases: infinitivo, gerundio y participio. En el presente trabajo nos proponemos presentar las construcciones perifrásticas más frecuentes, en sus tres variantes, en el castellano hablado por los niños del distrito de La Mar (Ayacucho), zona andina de contacto de lenguas donde el castellano evidencia el fuerte influjo de la lengua quechua.

«La frase compleja ESTAR+que en el castellano peruano»

Víctor Arturo Martel Paredes (Universidad Nacional Mayor de San Marcos)

En el presente estudio describiré la construcción Ella está que canta del castellano de la variedad peruana, en donde el verbo ESTAR aparentemente selecciona una frase complementante para conformar una predicación compleja. Mi propuesta será que ESTAR y el complementante se fusionan previamente para conformar una estructura aspectual de iteración. Seguiré la propuesta de Cuervo (2003) sobre la conformación de estructura eventiva para analizar los componentes de dicha construcción. Además, evaluaré una segunda hipótesis de hipersascenso, según la cual, debido a la ausencia de rasgos de chequeo de caso en FT subordinada, la FD sujeto escapa de su dominio a la posición de sujeto de ESTAR (Martins y Nunes 2010, Fernández-Salgueiro, 2005; Fong, 2019; Pesetsky y Torrego, 2001, 2004, 2007).

«Lexicogénesis: el caso de feminazi»

Raymundo Casas Navarro y Jasmin Ochoa Madrid (Universidad Nacional Mayor de San Marcos)

Desde que la lexicología inició su periplo por el maravilloso mundo del lenguaje, según la plausible expresión de Walter Porzig (1964), se interesó vivamente en los procesos mediante los cuales se enriquece el léxico efectivamente empleado en determinada comunidad de 
habla. Como establece Dressler (2000), en la lexicogénesis resulta rentable un nivel que se denomina paramorfología. Así, en virtud del conocimiento tácito del sistema de la lengua, surgen vocablos nuevos por un proceso de fusión (blending), los cuales son denominados palabras portmanteau en la literatura especializada. En la ponencia, se dilucidará los entresijos que se pueden barruntar en el proceso de onomaturgia (Migliorini, 1975), con especial incidencia en el término feminazi, creado por Tom Hazlett en el idioma inglés y transferido a la lengua castellana con naturalidad (especialmente, en redes sociales como Facebook). En efecto, se trata de un vocablo portmanteau que fusiona los términos «feminista»y «nazi», con el fin de construir una mirada peyorativa y denigrante de un sector radical y pujante del feminismo que recorre el mundo occidental. Así, como se observa onomaturgia en filosofía (verbigracia, «vivencia»), en ciencia (verbigracia, «escutoide») o en literatura (verbigracia, «perogrullada»), el proceso se puede hallar en la propia dinámica del lenguaje cotidiano (verbigracia, «mileurista»).

Sin embargo, debido a sus insoslayables connotaciones ideológicas, la palabra feminazi ha sufrido un sui generis proceso de ebullición, con usuarios entusiastas e indignados detractores, lo que podría servir para marcar una isoglosa de dimensión sociolectal. Por ello, urge un análisis lexicológico profundo que trate de esclarecer los mecanismos formales y semánticos involucrados en la creación y en la difusión de tal "palabra de autor». Aunque se puede notar que el uso del término tiene engarces con el fenómeno del ciberodio (online hate speech), nuestra intención es dar cuenta de la referida onomaturgia en términos de una explicación basada en los vectores de la cognición, el lenguaje y la cultura.

«Las denominaciones de los lugareños de Lima Metropolitana y el Callao: surquillanos, santanitenses, villamarianos, chalacos $[\ldots]$ »

Claudia Garay Ramírez y Marco Lovón Cueva (Universidad Nacional Mayor de San Marcos)

Las denominaciones de los lugareños de los distritos o ciudades más importantes de un país no suelen ser estudiadas desde la lexicología 
https://doi.org/10.46744/bapl.201902.009

y la lexicografía. El objetivo de la presente ponencia es analizar las denominaciones de los distritos de la provincia de Lima, en esta se incluyen las referencias a los lugareños de los distritos de Lima Metropolitana (p. ej. limeño, molinero, surcano, magdalenense, etc.) y de la Provincia Constitucional del Callao (p. ej. chalaco).

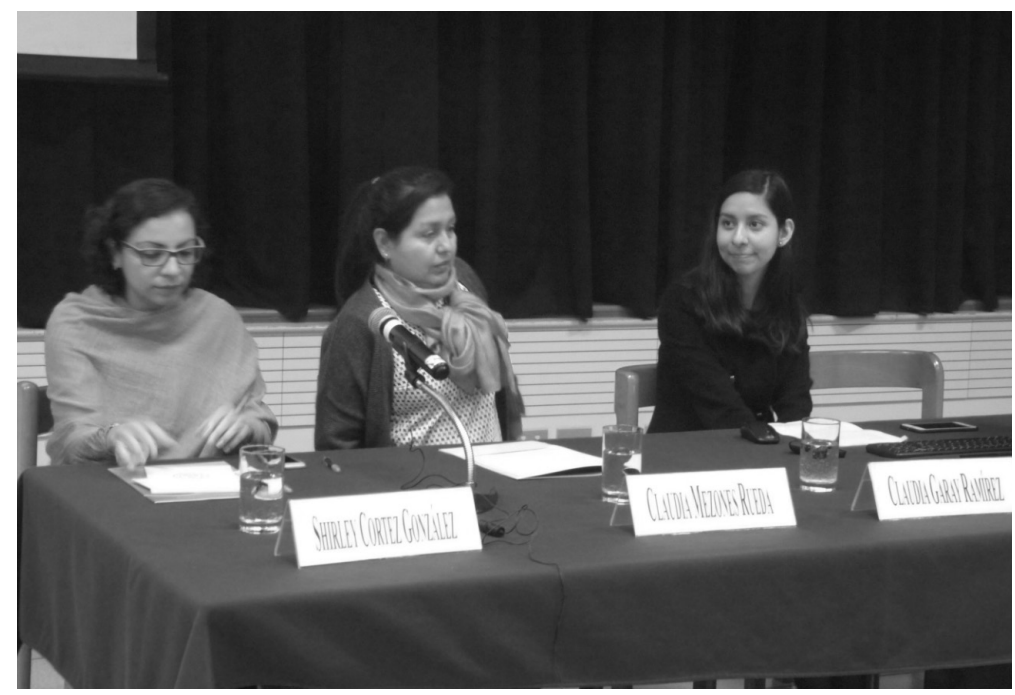

«Tratamiento lexicográfico de adjetivos y adverbios gramaticalizados en el uso del español americano»

Claudia Mezones Rueda (Universidad de Piura)

La ponencia pretende explicar el uso de distintas categorías de palabras que, por transposición o por variación de su significado, se usan con valores adverbiales o adjetivales y cómo parecen registradas en los diccionarios. Se parte del trabajo sobre un reportorio de palabras recogidas del uso del español peruano actual (por ejemplo, siempre, espeso, pésimo, quaker, de aquí, entre otros), para describir su gramaticalización adjetiva o adverbial. A partir de esto, se hará un análisis de contenido lexicográfico para explicar su tratamiento en el Diccionario de americanismos y el de Peruanismos, principalmente. 
«Fujinombres: la productividad de un apellido en el habla peruana actual» Shirley Cortez González (Universidad de Piura)

Sabido es que las palabras son, en cierta medida, una puerta para adentrarse en los intereses, necesidades, ideas y preocupaciones de una sociedad. Uno de esos intereses es, sin duda, la política, que incide no solo en el rumbo de un país, sino también en el habla de sus ciudadanos. En concreto, en este trabajo se abordará la influencia del partido político fundado por Alberto Fujimori, y continuado por sus hijos Keiko y Kenji, en el habla peruana desde fines del siglo xx en adelante. A partir de un corpus léxico tomado principalmente de la prensa escrita (digital) y de las redes sociales (sobre todo, Twitter), se analizarán los neologismos producidos por influencia de este partido político y de sus líderes, así como los mecanismos lingüísticos empleados por los hablantes, de los que resulta especialmente llamativo el neoprefijo fuji-, de lejos el más productivo.

«La oralidad como recurso expresivo de la novela Tantas veces Pedro, de Alfredo Bryce Echenique»

Carla del Rosario Zelada Feria (Universidad Peruana de Ciencias Aplicadas y Universidad de Piura)

La modalidad oral es natural, consustancial al ser humano y constitutiva de la persona como miembro de una especie (Tusón, 1999:27). Y la memoria es clave para que la manifestación de la oralidad se mantenga a lo largo de la historia de generaciones de hablantes y de aquellos que se atrevieron a escribir según su repertorio léxico que garantizaría la expresividad en su narrativa; muestra de ello son los diálogos, reflexiones, etc. de una serie de personajes reales o ficticios que forman parte de la narrativa o lírica que pueda vincularse con las personas de distintas latitudes. Este estudio pretende valorar aquellas frases léxico-semánticas consideradas por Bryce Echenique en su novela Tantas veces Pedro como recurso expresivo de su estilo literario. 


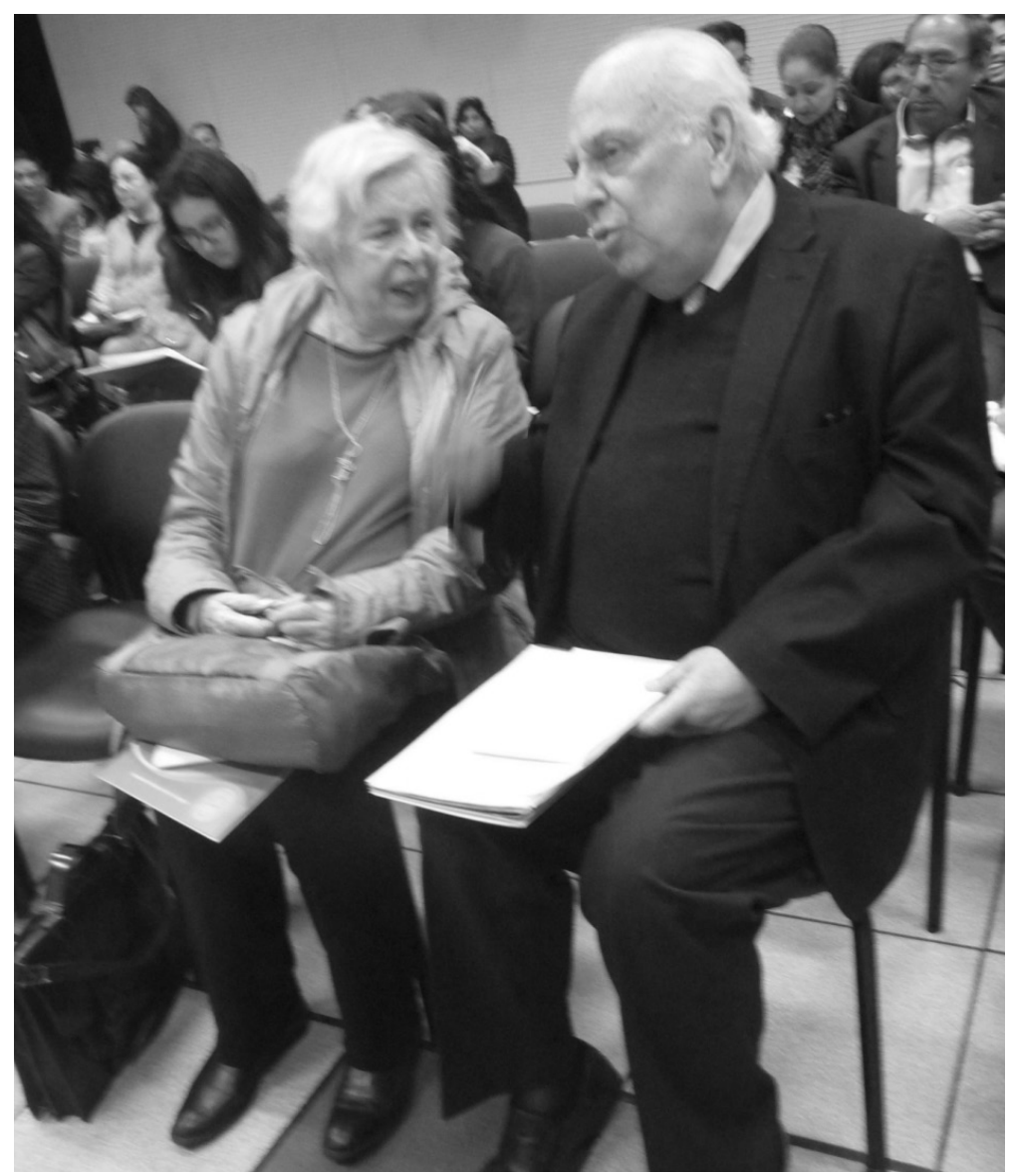

«Características léxico-semánticas de los titulares del diario Trome: un análisis desde la pragmática»

Úrsula Hernández Patrón (Pontificia Universidad Católica del Perú y Universidad de Piura)

Esta ponencia, derivada de mi tesis doctoral en curso, tiene como objetivo analizar el léxico empleado en los titulares del diario que ha 
llegado a ser el más vendido de habla hispana en el mundo: el diario peruano Trome. Para lograrlo, trazaré algunas reflexiones sobre las creaciones constantes de nuevos vocablos que se generan en el lenguaje coloquial a partir de factores extralingüísticos. El diario Trome es un objeto de estudio específico; sin embargo, su análisis puede permitir conocer usos lingüísticos inscritos en normas sociales y culturales que se establecen a partir de factores pragmáticos. El corpus utilizado para el análisis es de 365 titulares, los correspondientes a todas las publicaciones del 2018. Como conclusiones preliminares, he podido advertir el uso recurrente de metonimias, así como de mecanismos de atenuación, los cuales permiten generar una mayor empatía con los lectores.

«Redes sociales y lingua franca: el caso del léxico twitter»

Gloria Gabriel La Rosa y Ana Paola Yamada Ayala (Universidad Nacional Mayor de San Marcos)

A través de la presente ponencia, se pretende proponer una serie de artículos lexicográficos, así como sus correspondientes ejemplos de uso, empleados en la plataforma virtual Twitter. El estudio en cuestión constituye, en virtud de su dimensión descriptiva, una muestra compilada entre noviembre del 2013 y julio del 2019, tomada de un total de 1000 cuentas de Twitter, cuyos usuarios activos, durante el periodo de tiempo consignado anteriormente, tienen entre 15 y 50 años de edad, en tanto constituyen los grupos etáreos con mayor representatividad en la plataforma. Entre los resultados de la investigación se identifican 45 nuevas entradas (cuenta, hashtag, retuit, retuitear, trending topic, unfollow), trece nuevas acepciones (activo, va; avatar; mención; seguidor, ra; seguir; tendencia; usuario, ria.), 11 nuevas formas complejas, a saber, cuenta ( $\sim$ protegida), ( pública), $(\sim$ verificada $)$; dejar $(\sim$ de seguir $)$, etc. 


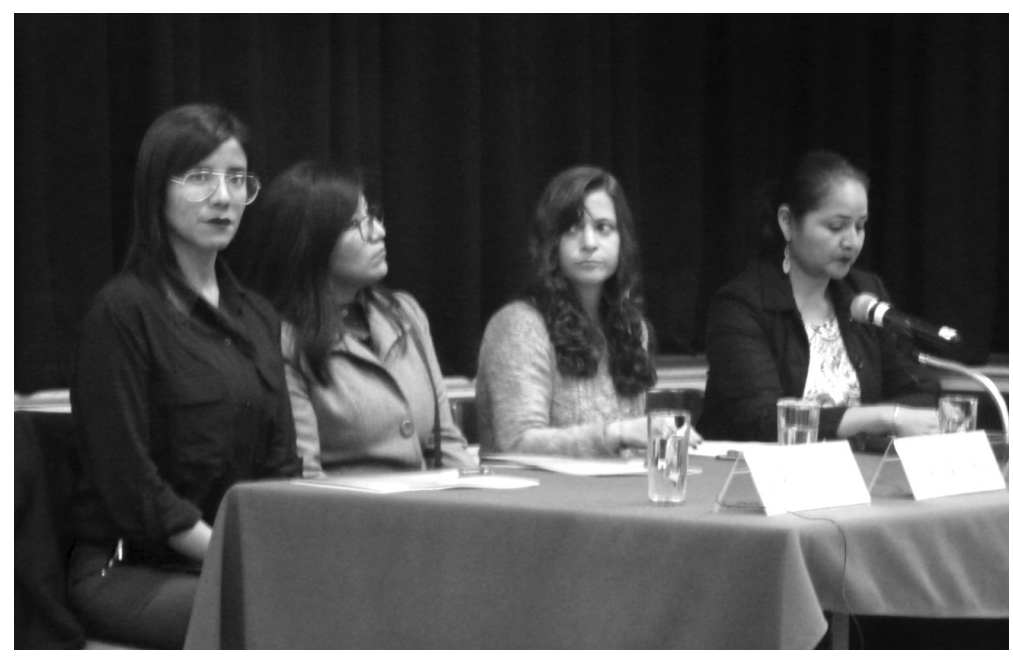

«La categorización sociosemántica del léxico huarochirano a partir del mundo animal»

Jeancarlo García Guadalupe (Universidad Nacional de Educación Enrique Guzmán y Valle)

En el presente artículo, se muestra y analiza, en primer lugar, cómo la construcción del significado de las unidades fraseológicas presentes en el español hablado en Huarochirí — las locuciones verbales, específicamente aquellas de estructura gramatical [ser/estar como] + [un/una] + [animal] — obedece inicialmente a prototipos psicológicos en el marco de la categorización de los animales, en el marco de la semántica cognitiva. En segundo lugar, se reporta sobre la base de la sociolingüística cognitiva, que en dicha categorización intervienen también ciertos estereotipos y, en consecuencia, la construcción final del significado responde tanto a información conceptual heredada de la categorización conceptual del mundo animal como a la información social que fija la población en Huarochirí. 
https://doi.org/10.46744/bapl.201902.009

«Análisis lexicográfico de los diccionarios sincrónicos bilingües aimaras» Alan Mamani Mamani (Universidad Nacional del Altiplano)

El propósito comunicativo es analizar la macroestructura y microestructura de los diccionarios sincrónicos bilingües aimaras a partir de los diccionarios publicados en los últimos años: Aymara Kastilla Aru Pirwa y el Gran diccionario aimara. Mediante la metodología del estudio de casos y el análisis del contenido lexicográfico, se conocerá la carencia de elementos lexicográficos en su organización de estas obras.

«Deficiencias y omisiones en el tratamiento de peruanismos en el Diccionario de la lengua española (DLE), de la RAE, 2014, 23. a edición» Ana Baldoceda Espinoza (Universidad Nacional Mayor de San MarcosGI Lexicología y Lexicografía, Lexi)

En el examen de artículos léxicos con la marca de peruanismo - y aquellos que debiendo tenerla no la tienen-, se formulan observaciones, análisis y comentarios sobre: a) lema (variante de lema o lema erróneo); b) artículo léxico (desdoblamiento faltante); c) étimo (erróneo, insuficiente, redundante, incierto, faltante); d) transcripción fonológica (faltante o errónea); e) glosa (errónea o insuficiente); f) marca gramatical (errónea); g) marca de nivel de uso (mal formulada); h) marca diatópica (faltante, insuficiente o errónea); i) significado (erróneo, parcial o inexacto); j) propuestas (nuevos artículos léxicos, acepciones o formas complejas); k) adaptación innecesaria de extranjerismos (al pasar al español); l) redundancia; $m$ ) registro de localismos (erróneos); n) ortografía (errónea), etc.

«Aspectos semánticos de las unidades fraseológicas en el discurso político: patrones de interacción conceptual en el castellano peruano»

Frank Domínguez Chenguayen (Universidad Nacional Agraria La Molina), Antonia Francisca Chávez y Marco Malca Belén (Universidad Nacional Mayor de San Marcos)

El discurso de los políticos en el ámbito de la prensa permite observar una serie de combinaciones de palabras —o unidades fraseológicas (UFS)— 
que emplean los usuarios del castellano peruano con un significado unitario y con cierto grado relativo de fijación (e. g., comerse el pleito, meter la pata, traer algo hacia abajo, etc.). En esta comunicación exploramos los aspectos semánticos que configuran la expresión de estas unidades y, más exactamente, la construcción del significado que estas formas traen consigo en el castellano. Para ello, basándonos en los principios teóricos y metodológicos de la Lingüística Cognitiva, proponemos que dicho significado - el rasgo prototípico de idiomaticidad - se construye por el hispanohablante a partir de diversos patrones de interacción conceptual (expansión, reducción, entre otros).

«Alcances para un análisis lexicográfico de la fraseología peruana» Juan Quiroz Vela (Universidad de Piura) y Paola Arana Vera (Universidad del Pacífico)

El presente estudio forma parte de la disciplina de la Lexicografía, específicamente en el ámbito peruano. A pesar de que en la actualidad se vienen publicando con alguna regularidad artículos académicos, vocabularios y diccionarios en torno al léxico peruano, lo cierto es que el registro de las unidades fraseológicas muchas veces no es sistemático y, en ocasiones, puede llegar a ser confuso. Esta ponencia tiene el objetivo de dar cuenta del tratamiento fraseológico en las principales obras lexicográficas peruanas, es decir, la información que estos ofrecen, cómo se insertan en la macroestructura de vocabularios y diccionarios, y la calidad de sus definiciones.

«Superwoman, supermán, show-woman y showman...: los nuevos anglicismos de la lengua española»

Jessica Ramírez García (Universidad Católica Santo Toribio de Mogrovejo, USAT)

Este trabajo de investigación trata sobre el estudio de los extranjerismos utilizados en el siglo xxi en la lengua española —específicamente, de los anglicismos-, y tiene en cuenta la postura que adopta la Academia, al respecto, en sus principales publicaciones. Además de hacer una distinción entre el significado de préstamo, extranjerismo y adaptación 
gráfica, se hace mención de los extranjerismos crudos que incorpora la vigésima tercera edición del Diccionario de la lengua española (2014) — también las versiones electrónicas 23.1 y 23.2-, así como de las nuevas adaptaciones gráficas que surgen en sustitución de las voces extranjeras. Asimismo, se han realizado consultas de los anglicismos que aún se conservan solo como extranjerismos crudos en el Corpus de Referencia del Español Actual (CREA), el Corpus Diacrónico del Español (CORDE), el Corpus del Español del Siglo xxi (CORPES XXI) y el buscador Google, para visualizar y confirmar el uso real que se hace hoy de cada término.

«Flora de Pataz: una exploración léxica»

Edna Domínguez Domínguez (Universidad Nacional Mayor de San Marcos)

En la presente ponencia, nos proponemos identificar la denominación de las plantas que usan los habitantes en la provincia de Pataz, departamento de La Libertad. El método utilizado es el de la observación directa y la identificación con la información de habitantes conocedores de la región. Este trabajo es de capital importancia, pues permitirá el conocimiento fitonímico de las especies y la clasificación de los términos de acuerdo con la filiación lingüística y el conocimiento de sus propiedades medicinales. Finalmente, la especificación de la diversidad lingüística de las plantas será de gran utilidad para el estudio de las lenguas y el esclarecimiento de la etnohistoria de la región y del mundo andino.

«Lexicología de la fauna y la flora en el libro de Arkady Fiedler Los peces cantan en el Ucayali»

Mirosław Rajter (Universidad de Poznań, Polonia)

En el libro de Arkady Fiedler, Los peces cantan en el Ucayali (1935), el autor hace referencia a nombres de fauna, flora y de pueblos indígenas que habitan en la Amazonia peruana en la región Ucayali. El objetivo de la ponencia será analizar estos léxicos y sus cambios a través del tiempo, sus sinónimos y sus homólogos en otras lenguas nativas de la región, así como en latín. 


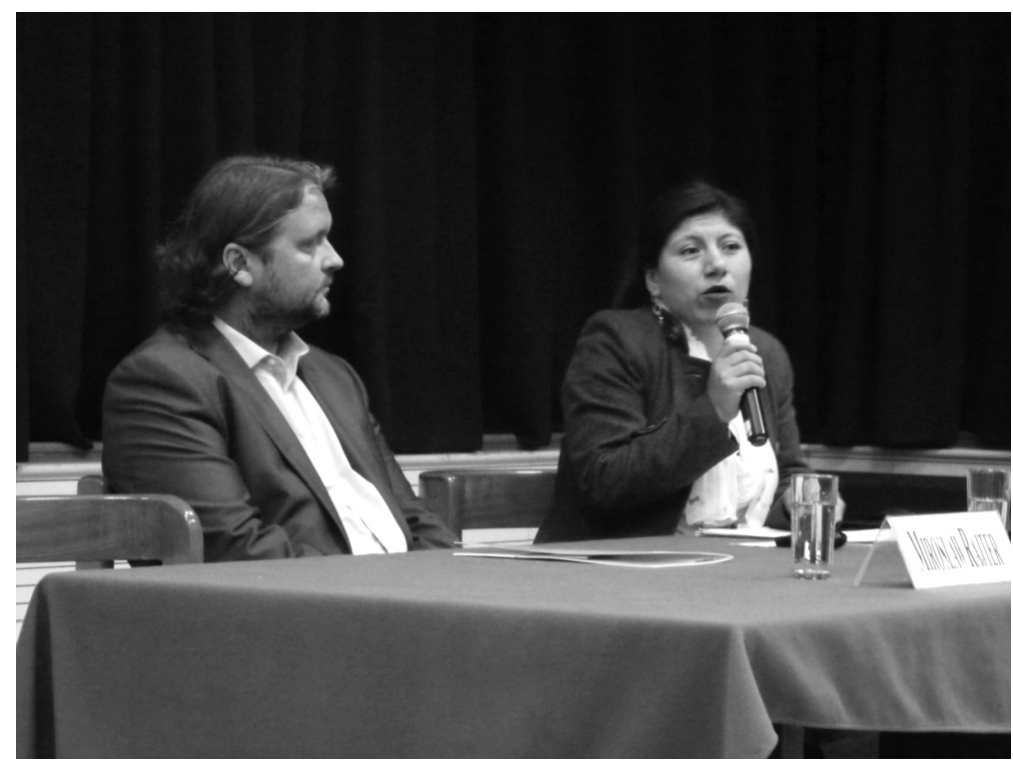

Adriana Valdés Budge, directora de la Academia Chilena de la Lengua, cerró el Congreso con su conferencia titulada «Lexicografía de cara al público y al país, 2019: actividades de la Academia Chilena».

«Las ponencias del Congreso han sido de gran nivel y han dado testimonio del profesionalismo, y la acuciosidad del trabajo lexicográfico que se realiza en el Perú», afirmó. «Para todos nosotros han tenido información bienvenida y a veces sorprendente, que abre caminos a la reflexión lexicográfica».

«En particular interesan, desde la perspectiva de ASALE, creo, y de la mía propia, ciertamente, las variantes del castellano de los bilingües cuya lengua materna no es el español, y la de sus hijos, cuya lengua materna ya es el castellano», agregó. «El tema del castellano andino me llega personalmente muy hondo: hace ya muchos años que no dejo de pensar y de escribir acerca de César Vallejo, grandísimo poeta que mientras más se lee más se admira y más maravilla produce». 


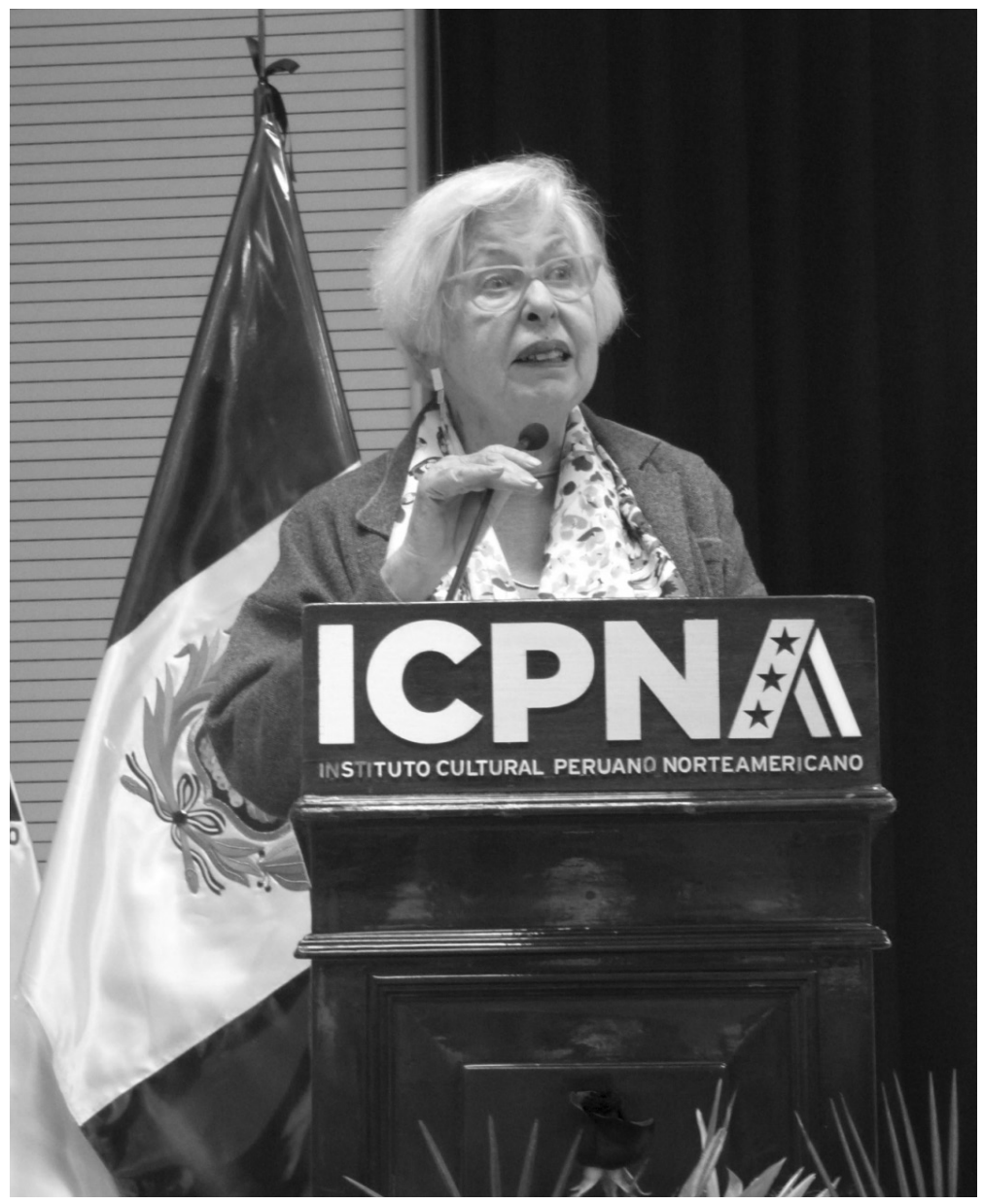

La directora de la Academia Chilena se refirió al llamado «lenguaje inclusivo», una preocupación que se abordó en dos de las ponencias durante el Congreso. "Debo contarles que en Chile, en los años 2018 y en el actual, este dejó de ser un tema lexicográfico para transformarse en una bandera de lucha estudiantil», afirmó. 
«Nuestra académica correspondiente doña Alejandra Meneses debió presentar ante el Consejo Superior de su universidad, la Pontificia Universidad Católica de Chile, un planteamiento lingüístico-político de la máxima urgencia, mientras había facultades en toma y letreros alusivos cerrando las puertas de la Casa Central de la Universidad... La Academia Chilena decidió recoger el magnífico material de reflexión lingüística presentado por ella, complementarlo con el trabajo de sus propias comisiones de lexicografía y de gramática, y hacer por primera vez en la historia de la Academia una conversación pública, de cara a los periodistas que no cesaban de preguntarme por eso (en mi condición de primera mujer directora de la Academia), a las organizaciones de mujeres, a los participantes invitados por redes sociales y al público en general». Acotó que en la página electrónica de la Academia Chilena se puede encontrar la conversación completa.

Asimismo, informó que el Congreso de Chile, la Cámara de Diputados, invitó a los académicos participantes a presentar ante ellos el tema y entablar una conversación sobre el tema en el Poder Legislativo. «Este diálogo con la prensa, con las universidades y con los poderes del Estado de Chile llena de orgullo a la Academia», enfatizó.

Adriana Valdés Budge anunció también que la académica correspondiente Irene Renau encabezará un taller titulado «Cómo leer los diccionarios» orientado a profesores, periodistas y público general.

«Solo me queda manifestar mi honda gratitud, en nombre propio y en el de la Academia Chilena de la Lengua, por la hospitalidad intelectual y muy especialmente la hospitalidad humana que nos ha brindado la Academia Peruana, la que encarnamos en la persona de su presidente, doctor Marco Martos», acotó. «Su incansable esfuerzo por organizar de manera inmejorable este encuentro, de facilitar todas las condiciones para una participación eficaz e interesantísima, comprometen nuestro agradecimiento. A ello debemos agregar las excelentes conversaciones que se han producido entre nosotros tanto dentro como fuera de esta sala, siempre en torno a lo que Alfredo Matus ha llamado «enamorados 
https://doi.org/10.46744/bapl.201902.009

del lenguaje», y sobre todo de la poesía, que él tan bien encarna. No puedo dejar de mencionar que ha sido fundamental la actividad incesante y discreta de su asistente, doña Magaly, y la cooperación de todos los que contribuyeron a la organización del Congreso».

El viernes 11 por la mañana, antes de la tercera y última sesión del Congreso, se procedió a la entrega de premios del III Concurso Literario Escolar de la Academia Peruana de la Lengua en el salón de actos de la casona señorial compartida por varias academias.

Marco Martos Carrera, presidente de la Academia Peruana, abrió el acto reiterando lo que había dicho al inaugurar el Congreso de que en 1892, en el 400 aniversario del viaje de Cristóbal Colón, y en representación de su Academia, Ricardo Palma «llevó a España varias palabras para el Diccionario y no le aceptaron ninguna»; pero agregó que con el tiempo fueron incorporadas. «Estamos conmemorando el centenario de su fallecimiento», aclaró.

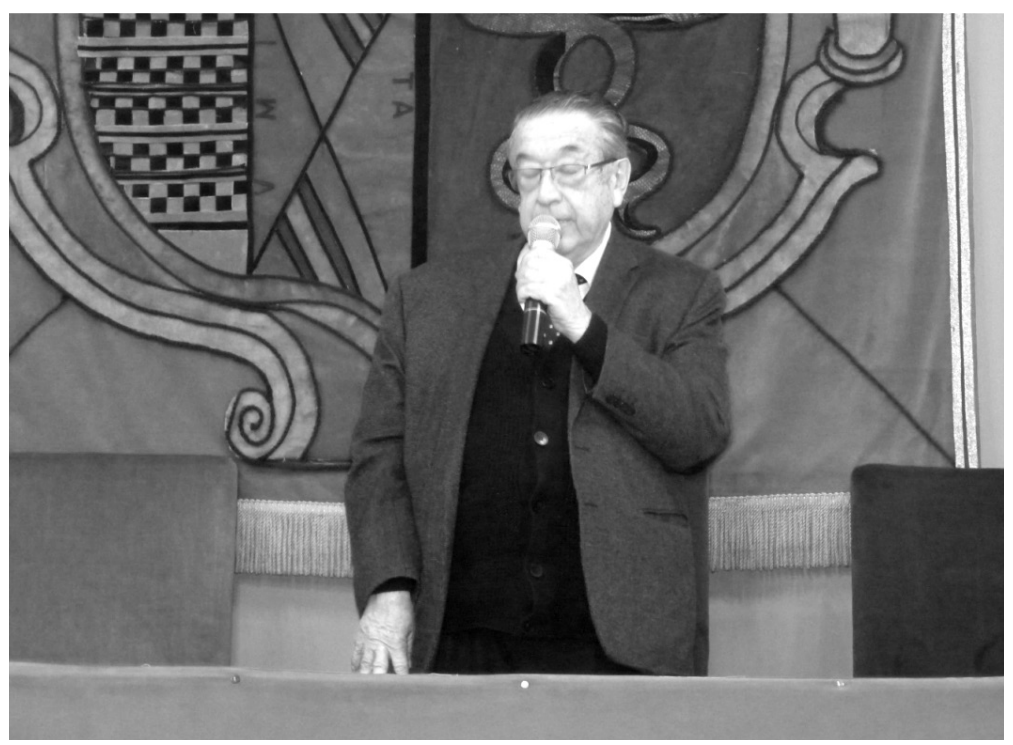


https://doi.org/10.46744/bapl.201902.009

«Una tarea de nuestra Academia es buscar el acercamiento del mayor número de peruanos, de acercamiento a los estudiantes», agregó. «Desde hace tres años hacemos este concurso con los estudiantes». E indicó con sorpresa que las cuatro ganadoras de este año provenían del mismo colegio. «Ustedes provienen de uno de esos colegios que son algo así como locomotoras de la educación», sentenció. "Nos entusiasma mucho que haya habido concursantes de muchos sitios de Perú. Y ustedes son las justas vencedoras». La Academia Peruana premió con computadoras portátiles a las dos primeras, y con tabletas, a las dos siguientes, además de diplomas.

Las ganadoras, todas del Colegio Mayor Secundario Presidente del Perú (COAR), Lima, fueron:

\section{Categoría I}

Primer premio: Allison Jazmín Domínguez Fernández por «El conde de Lemos y la fragilidad animal del siglo xx».

Segundo premio: Joyce Katheryn Gonzáles Llerena por «El talento del conde de Lemos».

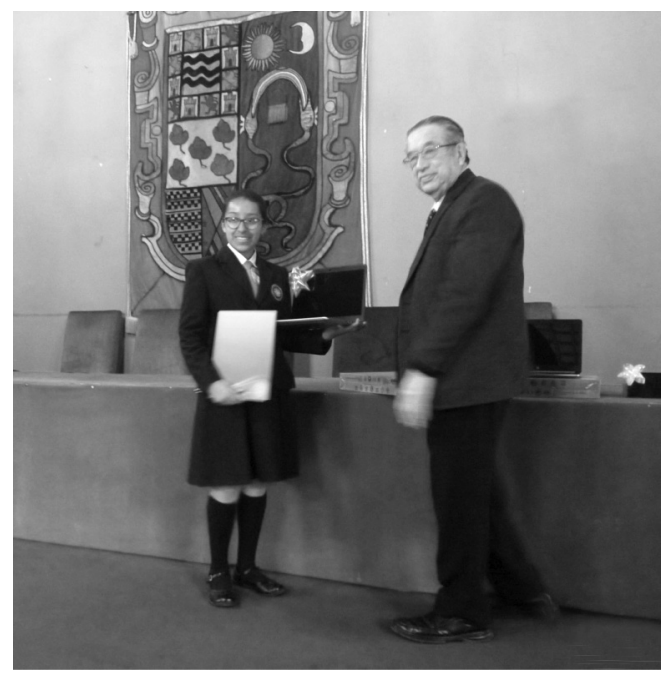


https://doi.org/10.46744/bapl.201902.009

\section{Categoría II}

Primer premio: Kattia Jimena Zavala Contreras por «"La danza de las horas", un llamado a la vida provinciana».

Segundo premio: Yaneli Elisa Benavídes Westreycher por "Abraham Valdelomar: los recuerdos de la niñez y juventud expresados en "Los ojos de Judas" y "El buque negro"».

En representación del profesorado del Colegio, se presentó el docente de literatura Miguel Ángel Carhuaricra Anco. También se dejó constancia de reconocimientos a las tutoras de las ganadoras Rosa Ysabel Palomino Linares, Rocío Parra, Ana Estrada Ocaña, como también al mismo Carhuaricra. Entregaron los premios el presidente de la Academia Peruana Marco Martos Carrera, el director honorario de la Academia Chilena Alfredo Matus Olivier, y el secretario general de la Academia Norteamericana Jorge Ignacio Covarrubias. 